\title{
Mapeamento da Antiga Cobertura Vegetal de Várzea do Baixo Amazonas a Partir de Imagens Históricas (1975-1981) do Sensor MSS-Landsat
}

\author{
Vivian Fróes RENÓ ${ }^{1}$, Evlyn Marcia Leão Moraes NOVO$^{1}$, Raimundo ALMEIDA-FILHO ${ }^{1}$, \\ Chieno SUEMITSU ${ }^{2}$
}

\begin{abstract}
RESUMO
Este estudo apresenta um mapa da cobertura vegetal da planície de inundação do Rio Amazonas entre as cidades de Parintins (AM) e Almeirim (PA), com base em imagens Landsat-MSS adquiridas entre 1975 e 1981 . O processamento digital dessas imagens envolveu a transformação para imagens-fração de vegetação, solo e água escura (sombra), seguido da aplicação de técnicas de segmentação e classificação por região. O mapa resultante da classificaçáo foi organizado em quatro classes de cobertura do solo: floresta de várzea, vegetação não-florestal de várzea, solo exposto e água aberta. A precisão do mapa foi estimada a partir de dois tipos de informaçóes coletadas em campo: 1) pontos de descrição: para validação das classes de cobertura não sujeitas a grandes alteraçôes, como é o caso dos corpos d'água permanentes, e identificação de indicadores dos tipos de cobertura original presentes na paisagem na ocasião da obtenção das imagens (72 pontos); 2) entrevistas com moradores antigos para a recuperação da memória sobre a cobertura vegetal existente há 30 anos (44 questionários). Ao todo foram coletadas informaçóes em 116 pontos distribuídos ao longo da área de estudo. Esses pontos foram utilizados para calcular o Índice Kappa de concordância entre os dados de campo e o mapa resultante da classificação automática, cujo valor $(0,78)$ indica a boa qualidade do mapa de cobertura vegetal da várzea. Os resultados mostram que a regiáo possuía uma cobertura florestal de várzea de aproximadamente $8.650 \mathrm{~km}^{2}$ no período de aquisição das imagens.
\end{abstract}

PALAVRAS-CHAVE: sensoriamento remoto, mapeamento automático, floresta de várzea, Landsat-MSS.

\section{Mapping ancient vegetation cover of the Amazon floodplain using historical MSS/Landsat images (1975-1981)}

\begin{abstract}
This study presents a vegetation map of the Amazon River floodplain between the towns of Parintins (AM) and Almeirim (PA), based on Landsat-MSS scenes from 1975 to 1981. Digital processing involved the transformation of multispectral images into fraction-images of vegetation, soil and dark water (shadow), followed by the application of segmentation and region-classification techniques. The resulting map was organized four classes of land cover types: floodplain forest, non-forest floodplain vegetation, bare soil, and open water. Map accuracy was estimated from two types of ground data 1) sample points describing ground cover classes not subjected to major changes, such as permanent water bodies, and identifying indicators of the 30 year old vegetation type landscape (72 points); 2) interviews with community early residents for memory recovery of information on the vegetation cover existing in the 1970 (44 interviews). Altogether, 116 information points was collected along the study area. These points were used to calculate the Kappa Index for agreement between the four field-verified classes and the automatic classification, with value (0.78) indicates the good quality of the floodplain vegetation cover map. The region had $8650 \mathrm{~km}^{2}$ coverage of floodplain forest at the time of image acquisition.
\end{abstract}

KEYWORDS: remote sensing, automatic mapping, floodplain forest, Landsat-MSS.

\footnotetext{
1 INPE - Instituto Nacional de Pesquisas Espaciais (DSR/OBT) Caixa Postal 515 - 12201-970 - São José dos Campos - SP, Brasil. E-mail: (vivianfr, evlyn, rai)@dsr.inpe.br

2 UFPA - Universidade Federal do Pará, Campus de Santarém. Avenida Marechal Rondon s/n. 68040-070, Santarém-PA. E-mail: chieno@ufpa.br
} 


\section{INTRODUÇÃO}

As florestas de várzea da bacia amazônica são ecossistemas ricos em recursos naturais e de grande importância ecológica, econômica e social. $\mathrm{O}$ desflorestamento nestas áreas gera impactos não só nos ecossistemas terrestres, como também na biodiversidade dos sistemas aquáticos (Costa et al., 2007), na circulação da água nas várzeas (Barbosa, 2005), na produção pesqueira, na qualidade da água e na saúde das populaçôes ribeirinhas (Novo et al., 2007).

Um estudo de Hess et al. (2003) utilizando imagens de radar adquiridas em 1996 mostra que a cobertura vegetal de várzea dos rios Amazonas/Solimóes apresenta diferença significativa entre a regiấo à montante de Manaus e a sua jusante. Segundo os autores, florestas inundáveis dominam a paisagem a montante da foz do Rio Negro, enquanto a jusante a vegetação é predominantemente herbácea e arbustiva. Estudos anteriores não são conclusivos quanto à natureza dessa diferença florística. Para alguns autores (e.g. DNPM, 1976) ela está associada a fatores naturais, como por exemplo, posição geográfica e hidroperíodos (Wittmann et al., 2004; Wittmann et al., 2006), enquanto outros (e.g. Barros e Uhl, 1997; IBGE, 2004; Winklerprins, 2006) afirmam que os campos de várzea a jusante da foz do Rio Negro são, em grande parte, resultado da atividade antrópica.

A ocupação das ilhas e margens da planície de inundação do Rio Amazonas é antiga, havendo relatos de ocupação muito antes do descobrimento do Brasil (Denevan, 1996; Roosevelt, 2000). No século XIX, extensas áreas das planícies de inundação foram desflorestadas para dar lugar a plantaçóes de cacau. Entretanto, foi a introdução da juta nas primeiras décadas do século passado a principal responsável pelo desflorestamento das várzeas. Estudos realizados por Winklerprins (2006) mostram que a produçáo de juta praticamente dominou a atividade agrícola de Manaus a Santarém entre os anos de 1930 e 1990. Segundo o autor, a cobertura vegetal da planície nessa regiáo é diversificada, consistindo de uma mistura de floresta nativa, floresta em regeneração, campos naturais e áreas cultivadas. Atualmente essas áreas encontram-se novamente sob pressão antrópica, em vista das políticas de controle do desflorestamento em terra firme. Em função disso, a atividade pecuária tem migrado para a planície aluvial, limitando a regeneração da cobertura vegetal de várzea (Smith, 1999; Winklerprins, 2006).

A atividade pecuária na várzea não é um fenômeno recente, no entanto. Na regiáo de Santarém ela teve início por volta de 1661 com o estabelecimento de uma missão comandada por europeus. Tratava-se de um sistema extensivo de criação que usava as abundantes gramíneas da várzea quando o rio estava baixo e deslocava o gado para as terras mais altas, ou para currais sobre estacas (marombas), nos períodos de cheias (Bunker, 1982). Desde então, a pecuária tornou-se uma alternativa de renda para as comunidades ribeirinhas, especialmente durante o período de cheia, quando há redução da produção pesqueira. Políticas públicas estabelecidas por meio de incentivos fiscais para a ocupação da Amazônia fizeram com que ocorresse grande aumento da atividade pecuária de várzea nas últimas décadas. A criaçáo de novas áreas de pastagem em terra firme, próximas às várzeas, possibilitou que o rebanho pudesse ser deslocado da várzea para essas novas áreas durante os períodos de cheia. Isso fez com que o número de cabeças de gado aumentasse muito, já que deixou de ser limitado ao pouco espaço disponível nas marombas e nas áreas mais altas da várzea (McGrath et al., 2006).

Outros fatores também impulsionaram o desflorestamento em áreas da várzea. Segundo Barros e Uhl (1997), no final dos anos 1950, instalaram-se na região do Baixo Amazonas grandes serrarias que passaram a explorar seletivamente as florestas de várzea. Somente a partir de 1970, com a abertura de estradas oficiais, deu-se início à exploraçáo de madeira em terra firme. Apesar de a exploraçáo madeireira nestas áreas ter maior lucratividade, o rendimento de pequenas serrarias familiares localizadas na várzea também é alto, se for considerada a taxa interna de remuneração do capital investido em relação a outras atividades econômicas na várzea. Por essa razão, cerca de mil serrarias desse tipo foram instaladas na regiáo do Baixo Amazonas e estuário entre as décadas de 1980 e 1990 (Barros e Uhl, 1997).

Em vista desse cenário, a hipótese deste trabalho é que a diferença verificada na cobertura vegetal de várzea - a jusante e montante de Manaus - não é apenas devida a fatores naturais, mas possui também um componente importante de interferência antrópica. Com base nessa hipótese, o presente trabalho objetivou mapear a antiga cobertura vegetal - com ênfase nas áreas florestadas - de várzea de um trecho do Baixo Amazonas a partir de imagens históricas (1975-1981) do sensor MSS (Multispectral Scanner System) dos satélites da série Landsat.

Os dados históricos resultantes deste trabalho, comparados a dados recentes da cobertura vegetal de várzea, permitirão avaliar a extensão do desflorestamento ocorrido no período. Se agregados a dados das décadas de 1980, 1990 e 2000 este trabalho poderá fornecer informaçóes valiosas sobre a evoluçáo do processo de desflorestamento ao longo dessas décadas, permitindo uma melhor avaliação de seus impactos sobre as várzeas.

\section{Área de Estudo}

Centrada na cidade de Santarém, a regiáo de estudo se estende por cerca $600 \mathrm{~km}$ ao longo das margens do Rio Amazonas, entre as cidades de Parintins (AM) e Almeirim (PA) (Figura 1). 


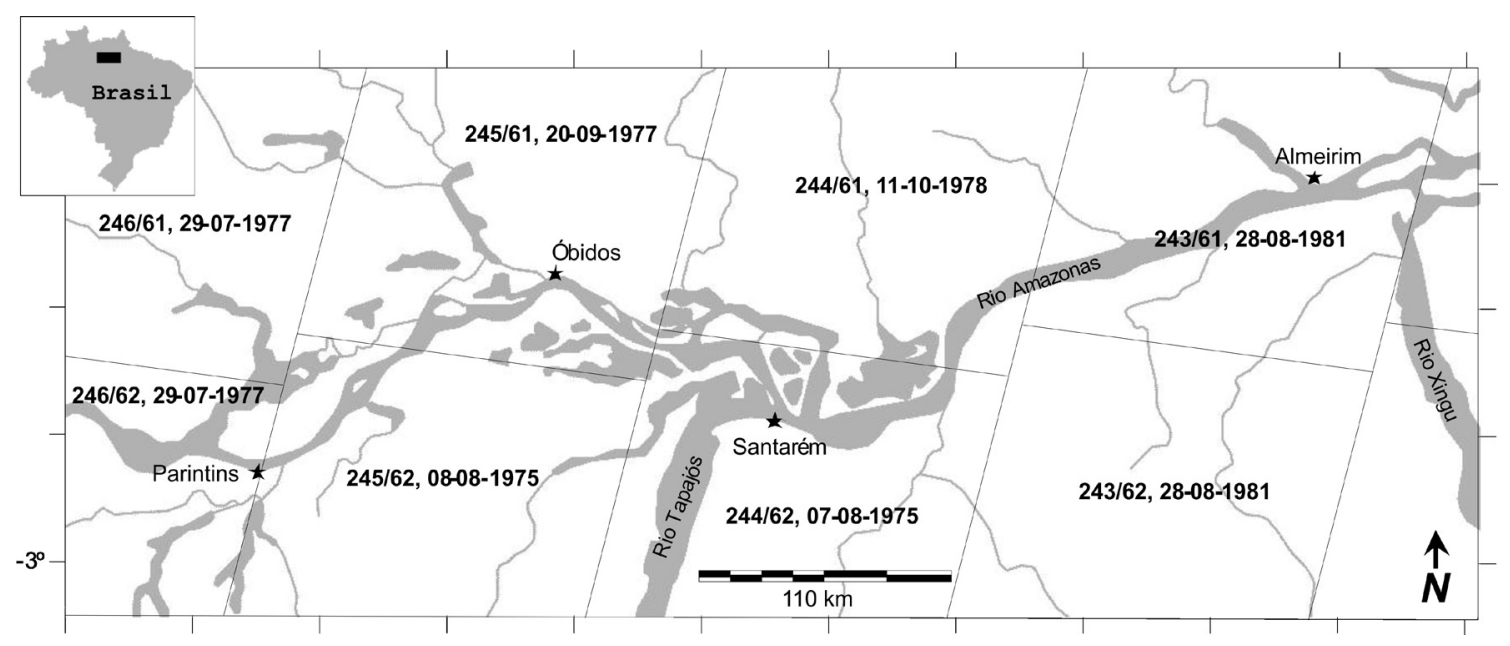

Figura 1 - Localização da região de estudo e grade de cobertura com as imagens Landsat-MSS analisadas no estudo, indicando órbita/ponto e datas de aquisição.

De acordo com Sheikh et al. (2006), a área de estudo faz parte da região do Baixo Amazonas, que se estende desde a divisa entre os estados do Amazonas e do Pará, até a confluência do Rio Xingu. Em contraste com a região a montante de Manaus, que se caracteriza por lagos em forma de canais e cobertura vegetal de várzea dominada por florestas $(70 \%)$, a regiáo a jusante se caracteriza pela presença de lagos de formatos arredondados, e apenas $10 \%$ da cobertura vegetal de várzea é constituída por florestas (McGrath et al., 2006).

Como a área de estudo está localizada a jusante de Manaus, pode ser considerada uma área teste significativa para a hipótese do trabalho. Além disso, cerca de 50\% dela faz parte do trecho de várzea mais afetado pela produção da juta, que vai de Manaus a Santarém.

\section{MATERIAL E MÉTODOS}

\section{Processamento Digital das Imagens Landsat-MSS}

Para cobrir a área de estudo foram utilizadas oito cenas Landsat-MSS (Figura 1); tendo sido priorizadas as imagens mais antigas, com menor cobertura de nuvens e em épocas próximas ao período de vazante do Rio Amazonas que, em geral, ocorre entre os meses de agosto, setembro e outubro.

A opção por imagens adquiridas próximas ao período de vazante levou em conta a baixa cobertura de nuvens relativa a este período, aliada a necessidade de reduzir os efeitos da amplitude de variaçấo anual do nível da água na região. Durante o período de seca (novembro) o nível mínimo médio de cota na regiấo é de aproximadamente três (3) metros, já no período de cheia (maio a junho) o nível máximo médio de cota é de 11 metros, ou seja, a amplitude de variação do nível da água na regiấo pode chegar a oito (8) metros entre as cotas máximas e mínimas (Barbosa, 2005). Essa grande variação no nível da água é o suficiente para expor temporariamente o fundo dos corpos d'água na seca e encobrir grande parte da cobertura vegetal herbácea e arbustiva na cheia, dificultando a recuperaçáo da informaçáo sobre a cobertura do solo. Dados de Barbosa (2005) baseados na análise da série histórica de cota para a régua de Curuai (ponto central da área de estudo) indicam que a cota média para o período de vazante é seis (6) metros, cerca de três (3) metros acima da cota mínima média para a regiáo.

Náo há como estimar a influência das variaçóes de cotas na extensão das áreas inundadas, nem seus impactos no mapeamento da cobertura vegetal de várzea, sendo possível, apenas, fazer algumas inferências a esse respeito. No tocante ao mapeamento da floresta de várzea, o pressuposto é de que seu mapeamento é pouco afetado por essas oscilaçóes de nível de água, porque as espécies vegetais dominantes neste tipo de formação florestal possuem de 10 a 45 metros de altura, dependendo do estágio sucessional (Wittmann $e t$ al., 2004; Wittmann et al., 2006), ocupando, além disso, as áreas topograficamente mais elevadas da várzea (Wittmann et al., 2004; Bispo et al., 2009). Pode-se aceitar, portanto, que durante o período de vazante o dossel da floresta permaneça emerso e detectável pelas imagens de satélite. Há de se considerar, no entanto, as implicaçôes das variaçôes de cota em relação aos demais tipos de cobertura da região. No caso de aumento do nível da água, grandes áreas de solo exposto e vegetação não-florestal podem ficar submersas e, portanto, subestimadas nas análises. Já a diminuição do nível da água pode deixar expostas áreas de solo antes submersas 
ou ocupadas por planta aquática, e, nesse caso, estas áreas seriam superestimadas. Esses tipos de cobertura, no entanto, não constituem objeto principal desta pesquisa. Além disso, o período de seca, quando a cota se mantém em torno de três metros, é bastante pequeno (menos de um mês) porque o nível da água volta a subir rapidamente, não permitindo o estabelecimento perene da vegetação. Esses motivos permitem aceitar a premissa de que o período de vazante seja o mais apropriado para o mapeamento da cobertura vegetal da várzea.

Baseada em dados da Agência Nacional de Águas (http:// www.ana.gov.br/), a Figura 2 mostra cotas médias diárias do Rio Amazonas na estação fluviométrica de Óbidos, referentes às datas de aquisição de cada uma das cenas MSS utilizadas, indicadas na Figura 1.

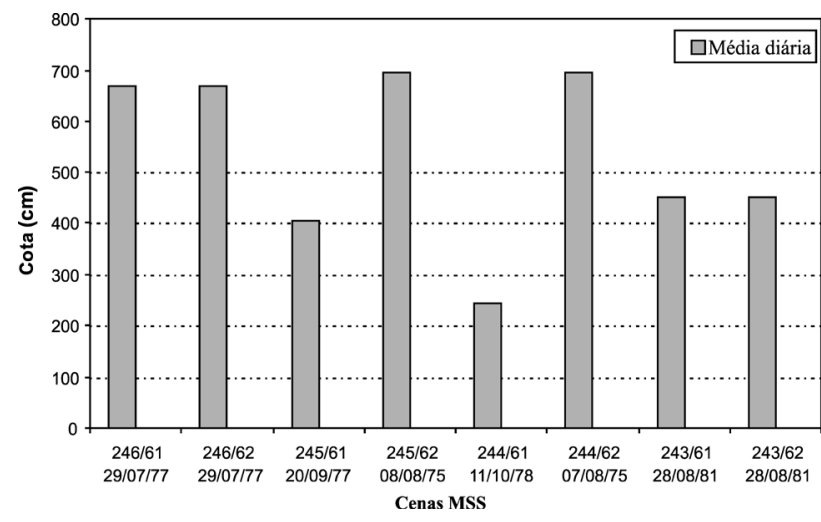

Figura 2 - Cotas médias diárias do Rio Amazonas em Óbidos nas datas de aquisição de cada uma das cenas Landsat-MSS utilizadas no estudo.

A análise da Figura 2 mostra que, nas datas de aquisição dessas cenas, o nível da água do Rio Amazonas não se encontrava mais do que um (1) metro acima da média para o período de vazante (seis metros). No entanto, na data de aquisição das cenas $244 / 61$ e $245 / 61$, os valores de cota estavam muito baixos, $2,42 \mathrm{~m}$ e $4,04 \mathrm{~m}$ respectivamente, característicos do período de seca. Por esse motivo, a amplitude de variaçáo do nível da água entre as cenas de maior cota $(244 / 62-6,95 \mathrm{~m})$ e menor cota $(244 / 61-2,42 \mathrm{~m})$ foi de $4,53 \mathrm{~m}$. Isso implica que, nas cenas de menor cota, as áreas mapeadas de solo exposto e vegetação não-florestal serão superestimadas, e as áreas mapeadas de água aberta serão subestimadas. Apesar do mapeamento dessas áreas não ser o objetivo principal desse estudo, essa diferença de cota pode acarretar em efeitos de descontinuidade no mapeamento das feiçôes, principalmente dos corpos d'água, nos locais onde há sobreposição entre as cenas.

O processamento das imagens Landsat-MSS foi realizado com o programa SPRING (Sistema de Processamento de Informaçōes Georreferenciadas), desenvolvido pela
Divisão de Processamento de Imagens (DPI) do Instituto Nacional de Pesquisas Espaciais (INPE) (Câmara et al., 1996). Primeiramente as imagens foram geometricamente corrigidas, utilizando como referência as cenas Landsat-TM (Thematic Mapper) ortorretificadas, disponíveis na base de dados "Global Land Cover Facility (http://glfc.umiacs.umd. edu)". O procedimento foi realizado com a identificação de pontos de controle bem distribuídos nas cenas e ajuste de um polinômio de $1^{\circ}$ grau para efetuar a associaçáo das coordenadas da imagem MSS com os pontos de controle na imagem de referência. O erro de posicionamento expresso pelo RMS (Root Mean Square) foi sempre menor que 0,90 pixel para todas as cenas; considerado aceitável por corresponder a menos de um pixel da imagem.

Após o registro foi aplicado o Modelo Linear de Mistura Espectral (MLME) nas bandas originais MSS4 (0,50-0,60 $\mu \mathrm{m}) ; \operatorname{MSS} 5(0,60-0,70 \mu \mathrm{m}) ; \operatorname{MSS} 6(0,70-0,80 \mu \mathrm{m})$ e MSS7 $(0,80-1,10 \mu \mathrm{m})$. Essa técnica (Shimabukuro e Smith, 1991) assume que o valor digital de um pixel da imagem representa a média das respostas espectrais dos diferentes componentes contidos nesse pixel, e utiliza uma relaçáo linear para representar a mistura da resposta espectral desses componentes. Assim, a resposta de cada pixel, em qualquer banda espectral, pode ser definida como uma combinaçấo linear das respostas de cada componente nele contido. Portanto, para qualquer imagem, se as respostas espectrais dos componentes puros são conhecidas, entấo as proporçôes dos componentes podem ser calculadas (Shimabukuro et al., 1998).

Para que o modelo possa ser aplicado é preciso definir com precisão os membros de referência (endmembers) que representarão o comportamento espectral dos componentes puros escolhidos para a geraçáo das imagens-fraçấo. Neste estudo foram obtidas diretamente de cada uma das oito imagens em nível digital (ND) as respostas espectrais dos seguintes componentes puros: solo, vegetação e água escura (sombra). A partir daí foi possível estimar as proporçóes de cada um desses componentes nas cenas Landsat-MSS, gerando as imagens-fração correspondentes. A adoção desse procedimento para o mapeamento da cobertura vegetal se deu, principalmente, por ser esse o procedimento adotado pelo PRODES para o mapeamento das áreas desflorestadas (Shimabukuro e Smith, 1991, Shimabukuro et al, 1998, Câmara et al., 2006).

Em seguida, as cenas foram recortadas para delimitar a regiáo correspondente às áreas de várzea. Os limites de corte foram definidos com base em uma máscara de áreas inundáveis elaborada por Hess et al. (2003) e Melack et al. (2004) a partir de imagens de radar em banda-L do satélite JERS-1 (Japanese Earth Resources Satellite-1). Todo o processamento subsequente foi realizado nas imagens recortadas. 
As imagens-fração foram submetidas a um algoritmo de segmentação; uma técnica de agrupamento de dados na qual as regiôes espacialmente adjacentes e de características espectrais semelhantes podem ser agrupadas. Para realizar esse processo é necessário definir dois limiares: a) o limiar de similaridade, que é a diferença mínima entre os níveis de cinza da imagem para a definiçấo de uma borda entre áreas, e; b) o limiar de área, valor de mínima dimensão, dado em número de pixels, para que uma regiáo seja individualizada. Neste trabalho as imagens fração (solo, vegetação e água escura) foram segmentadas pelo método de crescimento de regióes, utilizando os limiares de similaridade e de área iguais a oito (valor definidos após a aplicação de testes).

Em seguida, as imagens-fração segmentadas foram submetidas a uma técnica de classificação não-supervisionada por regiāo. O algoritmo é aplicado sobre um determinado conjunto de regióes, caracterizadas por seus atributos estatísticos de média, matriz de covariância e área. Esse algoritmo náo supóe conhecimento prévio sobre a distribuição de densidade de probabilidade dos dados. É uma técnica que permite agrupar regiōes (segmentos) a partir de uma medida de similaridade entre elas. No caso desse estudo, a medida de similaridade utilizada foi a distância de Mahalanobis entre a classe e as regióes candidatas a relação de pertinência com esta classe. A distância de Mahalanobis é definida pelo usuário a partir do limiar de aceitação, dado em percentagem. Quanto maior o limiar de aceitação, maior será a distância e, portanto, menor será o número de classes identificadas pelo algoritmo (Bins et al., 1993). Após diversos testes, foi definido um limiar de aceitação igual a $75 \%$, por ser o que melhor expressava o resultado das classificaçóes em termos de distribuição espacial das classes.

Para cada cena foram geradas entre 15 e 20 classes espectrais, as quais foram avaliadas contra a composição colorida das imagens-fraçáo e associadas às classes: floresta de várzea, referente à cobertura vegetal dominada por espécies arbóreas; vegetação não-florestal de várzea, referente a quaisquer outros tipos de vegetação que não fossem floresta; solo exposto, relativo às áreas de ocupação urbana, praias perenes e sedimentos recém expostos com a descida da água, e; água aberta, referente aos corpos d'água como rios, lagos e canais. Após a classificação das cenas individuais, estas foram justapostas para a formação de um mapa temático integrado.

\section{Dados de Campo}

Com o objetivo de avaliar os resultados da classificação das imagens, em termos da distribuição espacial das classes acima mencionadas, foi realizada uma campanha de coleta de dados de campo entre os dias 11 e 24 de junho de 2009. Na tentativa de avaliar os resultados da classificaçáo de imagens adquiridas há aproximadamente 30 anos, foram utilizadas duas abordagens distintas:
1) Aplicação de questionários junto às comunidades ribeirinhas, principalmente entre a população idosa, para a coleta de informaçóes sobre os entrevistados (idade, tempo de residência na comunidade, nível de alfabetização etc.); as características e condiçôes da comunidade (tipo de cobertura atual do solo, tempo de existência da comunidade, atividades de subsistência dos moradores, saneamento básico, educação etc.); e sobre possíveis modificaçôes que tenham ocorrido na paisagem da regiáo (tipo de cobertura do solo há 30 anos atrás, modificação na paisagem, recorrência, motivos etc.).

2) Descrição de pontos de campo, com coleta de informaçôes sobre estrutura, composição, diversidade e estágio sucessional da cobertura vegetal atual. Essas informaçóes forneceram indicadores do tipo de cobertura presente na paisagem na ocasião da aquisição das imagens históricas. Por exemplo, formaçôes primárias, ou seja, que se desenvolvem a partir de um espaço nunca antes ocupado, ocorrem em diversos estágios de desenvolvimento (desde praias ou substratos não colonizados até formaçóes florestais densas) e podem ser quebrados/interrompidos em qualquer estágio por fatores naturais ou antrópicos. Os indicadores são a composiçấo e a estrutura florística apresentada. O mesmo ocorre com formaçōes secundárias, que se formaram por regeneração após uma descaracterização do ecossistema primário. Assim, avaliando esses indicadores no presente, é possível inferir sobre o tipo de cobertura do passado e as possíveis causas de degradação, casa tenha ocorrido.

Para que os dados das entrevistas fossem relevantes para a avaliação do mapeamento era importante que o tempo de existência das comunidades entrevistadas, assim como a idade dos entrevistados e o tempo de residência destes na comunidade, fossem maiores que 30 anos. No entanto, devido à grande cheia do Rio Amazonas no período da campanha de campo, muitas comunidades de várzea encontravam-se total ou parcialmente abandonadas, dificultando a coleta de informaçóes.

Do total de comunidades visitadas, $91 \%$ existiam na área há mais de 30 anos, sendo $20 \%$ entre 30 e 50 anos e $71 \%$ com mais de 51 anos. Os restantes $9 \%$ náo possuíam esta informação. Apesar disso, em nenhuma das comunidades entrevistadas houve relatos de tempo de existência menor que 30 anos. Em relaçáo à idade e ao tempo de residência dos entrevistados, $68 \%$ possuíam idade igual ou maior que 45 anos, sendo que destes, apenas 10\% disseram residir na comunidade a menos de 30 anos.

Durante os 14 dias de campanha de campo foram feitas entrevistas em 44 comunidades e descriçóes em 72 pontos de campo, totalizando 116 pontos indicados na Figura 3. Como se pode constatar, a coleta de dados foi feita em diferentes pontos da regiáo de estudo, de forma a se obter uma boa espacialização e uma amostragem representativa dos diferentes 
tipos de cobertura. Para localizar as regióes em campo foi utilizado um sistema de posicionamento "Global Positioning System" (GPS).

Os dados de cada ponto de coleta foram analisados e rotulados de acordo com as classes pré-estabelecidas para a classificação das imagens, como mostram os exemplos a seguir:

1. Entrevistas realizadas na comunidade São Judas Tadeu, localizada no município de Prainha (S $1^{\circ} 53^{\prime} 39^{\prime \prime} / \mathrm{O} 53^{\circ}$ 29' $\left.17^{\prime \prime}\right)$, indicam que a área da comunidade era coberta por floresta de várzea na década de 1970. Por esse motivo o ponto foi rotulado como Floresta de várzea, mesmo que atualmente grande parte dessa área seja composta por outros tipos de cobertura vegetal. No caso dessa comunidade, foi entrevistada uma família de moradores antigos, incluindo o senhor Tadeu Araújo Brandão (65 anos), artesão, alfabetizado, nascido e criado na comunidade;

2. Dados coletados no Ponto A13 (S $2^{\circ} 15^{\prime} 16.3$ ” / O $\left.56^{\circ} 33^{\prime} 10.9^{\prime \prime}\right)$, município de Nhamundá, revelaram a presença de uma área de floresta de várzea de sucessão primária, com alta diversidade de espécies e com mais de 30 anos de existência. Neste local foram encontradas espécies arbóreas emergentes de até $40 \mathrm{~m}$ de altura, como a castanha-de-macaco (Couroupita subsessilis Pilg.), a sapucaia (Lecythis pisonis Camb.), a sumaúma (Ceiba pentandra), o angelim (Hymenolobium sp.) e grandes figueiras (Ficus sp.). Os troncos envelhecidos e expostos de algumas castanhasde-macaco estavam tomados por cactáceas epífitas robustas (Epiphyllum sp.). Também foram observadas espécies arbóreas e de palmeiras típicas de florestas de várzea ocorrendo de forma esparsa e freqüente, entre as quais o tarumá (Vitex cymosa Bert.), o uruará (Cordia hirsuta Fresen.), o mari-sarro
(Cassia grandis L.f.), o arapari (Macrolobium acaciifolium Mart \& Benth.), o jauari (Astrocaryum jauari Mart.), o tucumã (Astrocaryum aculeatum Meyer) e o marajá (Bactris major Jacq.). Além de lianas hemiepifíticas robustas da espécie Noranthea cf. e cebolas bravas (Clusia sp.), que são espécies características de ecossistemas florestais desenvolvidos e preservados, com, pelo menos, 30 anos de existência. Assim, devido à estrutura, composiçẫo, diversidade de espécies locais e indicação da presença de cobertura florestal há 30 anos atrás, o ponto foi rotulado como Floresta de várzea.

\section{Análise Estatística dos Resultados}

Depois de rotulados, os dados de campo foram plotados no mapa resultante da classificação automática das imagens, permitindo a geraçáo de uma matriz de confusão. Segundo Congalton e Green (1999), a matriz de confusão é um bom método para avaliar a qualidade da classificaçáo, pois descreve a exatidáo de cada classe com seus erros de comissão (quando um elemento é incluído em uma classe à qual ele não pertence) e omissão (quando um elemento é excluído da classe à qual pertence). Em seguida, a matriz foi utilizada como base para o cálculo do Índice Kappa (k), uma técnica de medida de exatidão que pode ser utilizada para determinar se uma matriz de erro é significativamente diferente de outra (Congalton e Green, 1999). Esta medida é baseada na diferença entre a exatidáo global (indicada pela diagonal da matriz) e a exatidáo de risco do produtor e do consumidor, que é indicada pelas somas das linhas e colunas da matriz de confusão, dada por:

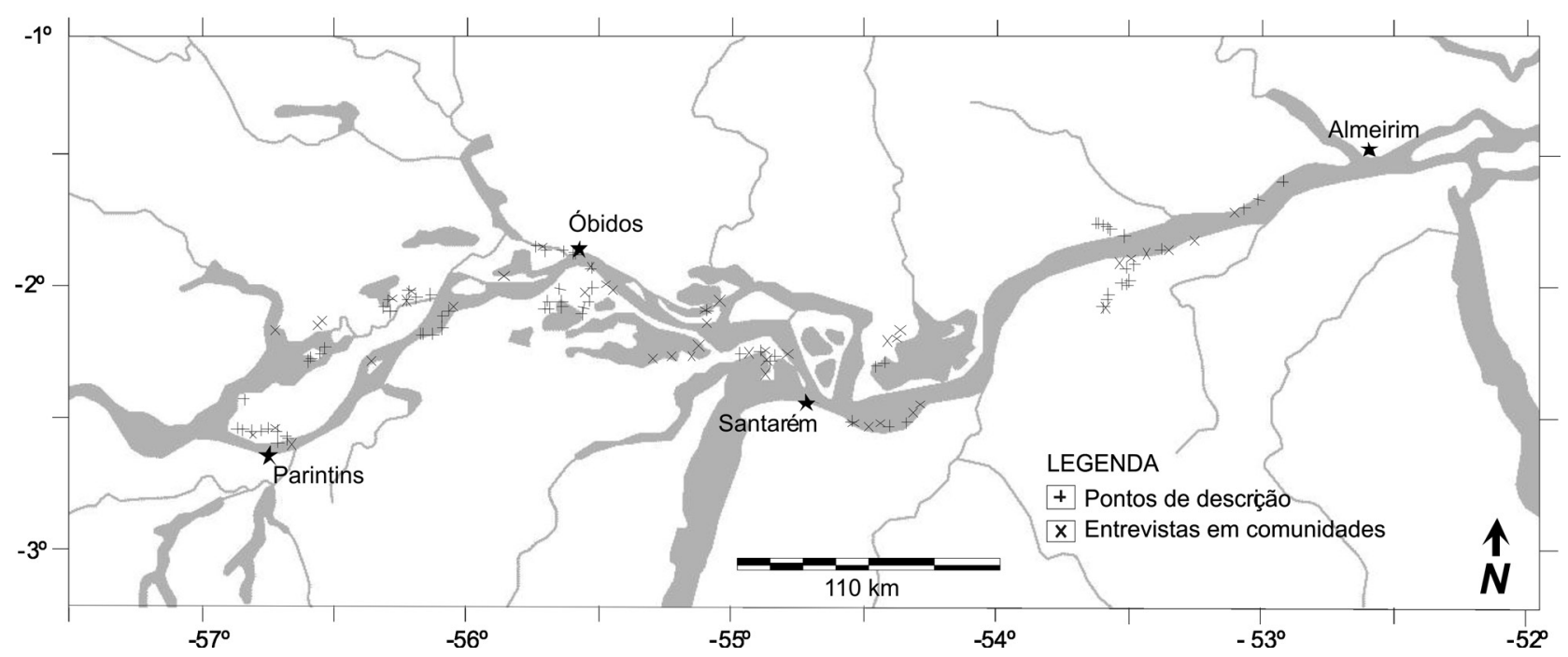

Figura 3 - Distribuição espacial dos pontos de coleta de dados, indicando descrição de pontos de campo (+) e entrevistas em comunidades ribeirinhas (x). 


$$
\mathrm{k}=\frac{\mathrm{N} \cdot \sum_{\mathrm{i}=1}^{\mathrm{r}} x_{i i}-\sum_{i=1}^{r} x_{i+} x_{+i}}{N^{2}-\sum_{i=1}^{r} x_{i+} x_{+i}}
$$

onde $\mathrm{N}$ é o número total de pixels na imagem, xii são os elementos diagonais da matriz e $x i+$ e $x+i$ representam os totais das linhas e colunas da matriz. $\mathrm{O} \mathrm{k}$ varia entre $0 \mathrm{e}$ 1 , sendo valores acima de 0,75 considerados "muito bons" a "excelentes", e valores abaixo de 0,4 considerados "ruins" (Mather, 2005).

\section{RESULTADOS E DISCUSSÃO}

\section{Mapa Histórico da Cobertura Vegetal de Várzea}

Após o processamento das imagens foi feito um mosaico das cenas classificadas, resultando em um mapa temático referente ao período de 1975-1981, indicado na Figura 4.

Ao contrário do esperado, as variaçóes de cota das cenas 244/61 e 245/61 não provocaram erros significativos de continuidade das feiçóes mapeadas, mesmo em relação à classe água aberta. Como essas cenas possuem cotas características do período de seca (três metros em média), a extensão de água aberta não se modifica drasticamente em comparação ao período de vazante (seis metros em média) porque, nessas condiçóes, as massas d'água se posicionam na planície num nível em que o terreno tem uma maior declividade. Assim, variaçôes de nível da água não correspondem a grandes variaçóes em área (Barbosa, 2005).

Os resultados indicam que entre 1975 e 1981, as áreas de floresta de várzea ocupavam cerca de $8.650 \mathrm{~km}^{2}$, as áreas com vegetação não-florestal perfaziam cerca de $7.730 \mathrm{~km}^{2}$, enquanto as áreas de solos expostos ocupavam cerca de $1.920 \mathrm{~km}^{2}$. A análise do mapa permite constatar a presença de formaçóes florestais em grande parte da área de estudo, inclusive entre Parintins e Santarém. Esta mesma região é apresentada no mapa de Hess et al. (2003) como dominada por vegetaçáo herbácea, o que indica que houve remoção de parte da cobertura florestal entre o período aqui analisado (1975-1981) e 1996.

O mapa obtido com as imagens históricas mostra uma marcante variaçáo no tipo de cobertura entre as metades oeste e leste da área de estudo. Assim, a montante da foz do Rio Tapajós predominam áreas de floresta de várzea, enquanto que a jusante, mais acentuadamente a partir do meridiano de $54^{\circ}$, ocorrem áreas de vegetação não-florestal. Esta diferença pode indicar variação no padrão de cobertura vegetal natural entre esses dois setores da área de estudo, ou pode ser devida a fatores antrópicos, indicando a substituição da cobertura de florestas de várzea originais. Nesse aspecto, deve-se considerar também que as cenas da órbita 243 foram adquiridas em 1981 e, sendo mais recentes que as demais (Figura 1), podem ter registrado mais sinais de atividades antrópicas.

\section{Análise dos Dados de Campo}

Muitos são os fatores que podem influenciar os resultados de uma classificação automática, tais como o tipo de sensor, época de aquisição da imagem, classificador etc. Por esse motivo, a mensuração do erro contido em um mapa temático resultante de classificação automática é importante para sua aplicabilidade.

Dado que existe uma diferença temporal de cerca de 30 anos entre as datas de obtençáo das imagens e o trabalho de campo realizado na regiáo, foram levantados dados que

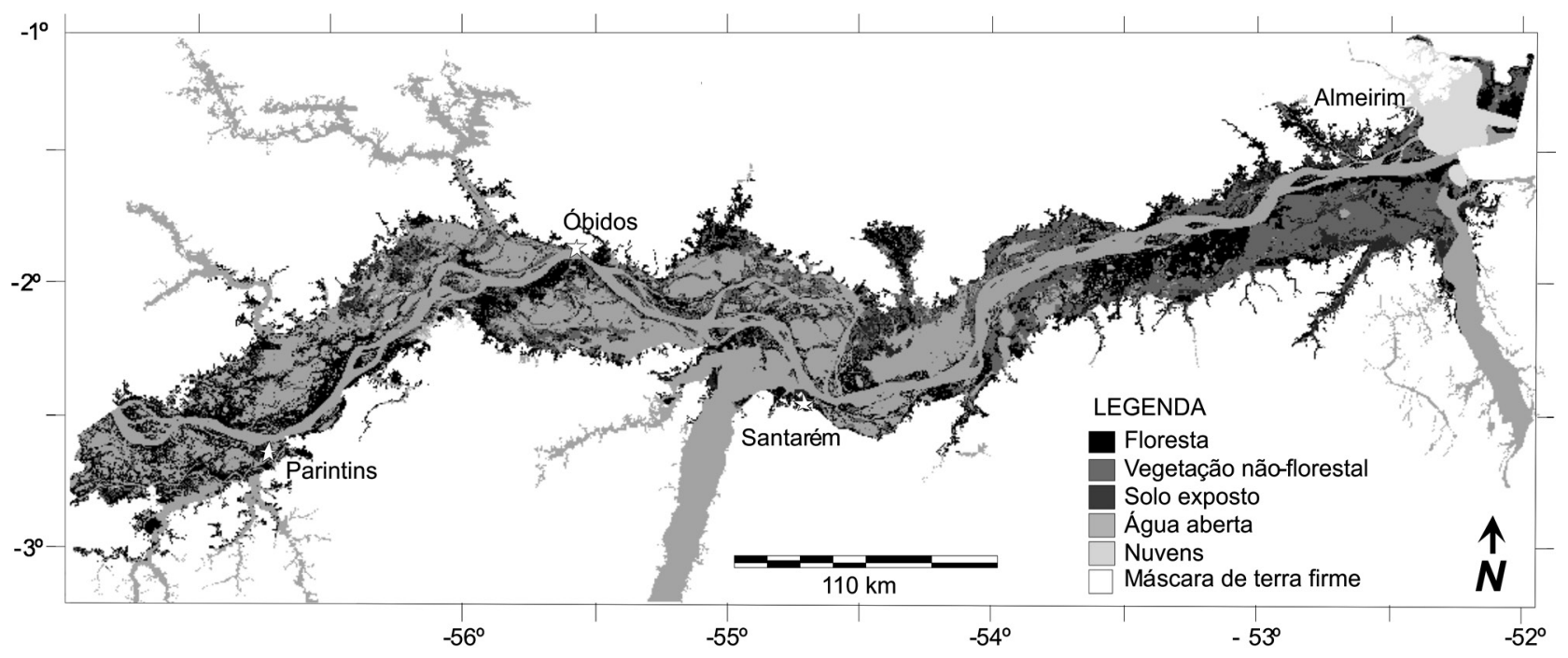

Figura 4 - Mapa de cobertura vegetal da região de estudo gerado a partir de classificação automática de imagens Landsat-MSS adquiridas entre 1975 e1981. 
permitissem estimar, mesmo que grosseiramente, o grau de mudança ocorrida nesse período. Para as áreas visitadas em campo, o erro temático do mapa resultante foi estimado através da construção de uma matriz de confusão e cálculo do Índice Kappa. A Tabela 1 apresenta a matriz de confusão que descreve a exatidão de cada classe com seus erros de omissão e comissão. de florestas de várzeas. Outra paisagem comum na região são as formaçôes pioneiras compostas por espécies arbóreas pioneiras que aparecem em ambientes perturbados durante o processo de regeneração da cobertura vegetal, como taxis da várzea (Triplaris surinamensis), embaúbas (Cecropia sp.) e mungubas (Pseudobombax munguba).

Tabela 1 - Matriz de confusão comparando os resultados da classificação (linhas) com os dados de referência de campo (colunas).

\begin{tabular}{|c|c|c|c|c|c|c|}
\hline \multirow{7}{*}{ 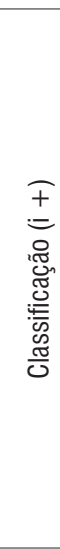 } & \multicolumn{6}{|c|}{ Referência de campo (+i) } \\
\hline & & Floresta de várzea & Vegetação não-florestal & Solo exposto & Água aberta & total $\left(x_{i+}\right)$ \\
\hline & Floresta de várzea & 58 & 4 & 4 & 0 & 66 \\
\hline & Vegetação não-florestal & 1 & 28 & 3 & 2 & 34 \\
\hline & Solo exposto & 0 & 0 & 7 & 1 & 8 \\
\hline & Água aberta & 0 & 0 & 1 & 7 & 8 \\
\hline & total $\left(x_{+i}\right)$ & 59 & 32 & 15 & 10 & 116 \\
\hline
\end{tabular}

A partir da matriz de confusão foi calculado do Índice Kappa. Além do Índice Kappa geral, também foram calculados os Îndices Kappa parciais de cada classe, indicados na Tabela 2.

Tabela 2 - Índice Kappa calculado para as diferentes classes de cobertura mapeadas na região de estudo.

\begin{tabular}{cc}
\hline Classe & Índice Kappa \\
\hline Floresta de várzea & 0,75 \\
Vegetação não-florestal & 0,8 \\
Solo exposto & 0,9 \\
Água aberta & 0,9 \\
Kappa Geral & 0,78 \\
\hline
\end{tabular}

Os valores do Índice Kappa, tanto parcial quanto geral, indicam uma boa concordância entre os dados obtidos em campo e o mapa temático resultante do processamento das imagens. Durante a campanha de campo foi possível observar que a atual cobertura do solo na região é composta por campos de várzea e capoeiras, entremeadas por remanescentes de florestas nativas e em regeneração. Algumas espécies residuais presentes nas áreas de vegetação secundária evidenciam um passado de várzea coberta por floresta densa e alta. Um exemplo típico é a presença da castanha-de-macaco (C. subsessilis Pilg.), que possui grandes frutos dispersados por mamíferos e roedores de grande porte. Também foram observados o arapari $(M$. acaciifolium Mart. \& Benth.), o mari-mari (Cassia leiandra), o tento vermelho (Ormosia sp.), o catauari (Crataeva tapia L.) e o louro (Ocotea sp.), que constituem espécies arbóreas clímaces
Das 44 comunidades entrevistadas, 33 relataram a remoção de cobertura florestal em seus arredores nos últimos 30 anos. A localização dessas comunidades no mapa classificado (Figura 3) indica que, dessas 44, 18 apresentavam cobertura florestal de várzea, 16 apresentavam cobertura de vegetaçáo não-florestal e apenas uma apresentava cobertura de solo exposto no seu entorno. $\mathrm{O}$ fato de 17 comunidades não possuírem cobertura florestal em 1975-1981 não significa, necessariamente, que não houve remoçấo de florestas. Muitas das atividades que impulsionaram o desflorestamento na várzea da regiáo tiveram início nas décadas de 1940 e 1950, portanto, o desflorestamento no entorno dessas comunidades pode ter ocorrido antes da época de aquisição das imagens utilizadas. Dentre os motivos relatados para a remoção da cobertura florestal estão:

1. o plantio da juta entre as décadas 1940 e 1990, relatado por $48 \%$ das comunidades entrevistadas, havendo relatos da prática desta atividade até os dias de hoje;

2. a criação de pastos para rebanhos bovinos, com início na década de 1950 , relatada por $42 \%$ das comunidades entrevistadas. A partir da década de 1970 houve a inserção do búfalo e a intensificação da atividade pecuária na várzea, que permanece forte atualmente;

3. o fenômeno de "terras caídas", que é o desprendimento das terras das margens dos grandes rios devido à velocidade das correntezas, relatada em $15 \%$ das comunidades entrevistadas, e; 
4. a retirada de madeira para abastecimento de barcos a vapor na década de 1950 e para consumo próprio das comunidades, relatada em 3\% das comunidades entrevistadas.

As entrevistas mostram que as comunidades possuem uma economia diversificada. Mais de $80 \%$ pescam e praticam a agricultura e a pecuária de forma conjunta e/ou alternada, e uma parte significativa cria pequenos animais. A atividade agrícola está presente em $91 \%$ das comunidades entrevistadas e a pesca em $86 \%$. Já a pecuária é praticada em $95 \%$ das comunidades, com um rebanho total estimado em mais de 260.000 rezes, somente em relação às comunidades visitadas.

Essas informações levam a crer que muitas das áreas identificadas por Hess et al. (2003) como campos alagáveis (vegetação herbácea), sejam de origem antrópica. Com o intuito de coletar mais informaçóes a respeito dessa questão, pretende-se, como próxima etapa, fazer o mapeamento da atual cobertura vegetal de várzea da região.

\section{CONCLUSÃO}

As informaçóes extraídas de imagens históricas do LandsatMSS, adequadamente processadas e confrontadas com dados de campo, podem ser utilizadas para recuperar informaçôes sobre a antiga cobertura vegetal de várzea.

As técnicas de processamento digital utilizadas para extrair as informaçôes das imagens Landsat-MSS mostraram-se adequadas, possibilitando a identificação e o mapeamento das classes pré-estabelecidas no trabalho. Do mesmo modo, os métodos utilizados para a coleta de dados em campo permitiram inferir sobre o antigo estado da cobertura vegetal na região estudada.

Embora a cobertura atual não tenha sido ainda mapeada para comparaçáo, os resultados sugerem que, ao longo dos últimos 30 anos, a regiấo teve parte de sua cobertura florestal removida, principalmente para o cultivo da juta e a criação de pastos, sendo atualmente ocupada por vegetaçáa predominantemente herbácea e arbustiva. Por esse motivo, os resultados reforçam a hipótese inicial deste trabalho, de que a diferença identificada na cobertura vegetal de várzea dos rios Amazonas/Solimóes possui um componente importante de origem antrópica.

\section{AGRADECIMENTOS}

Os autores agradecem ao geógrafo Diego Pinheiro de Menezes, do Instituto de Pesquisas Ambientais da Amazônia (IPAM), o fornecimento dos dados sobre a localizaçáo de comunidades ribeirinhas na área de estudo; à Da. Luciana Londe a presteza na revisão desse texto; à FAPESP o suporte ao trabalho de campo (Projeto 08/07537-1); e ao CNPq a bolsa de Vivian Fróes Renó no Programa de Pós-Graduaçáo em Sensoriamento Remoto do INPE (Processo 133327/2008-6).

\section{REFERÊNCIAS BIBLIOGRÁFICAS}

Barbosa, C.C.F. 2005. Remote sensing of water circulation dynamics to the Curuai floodplain/Amazon River. Tese de Doutorado em Sensoriamento Remoto, INPE, São José dos Campos, SP. (in Portuguese).

Barros, A.C.; Uhl, C. 1997. Logging along the Amazon River and estuary: Patterns, problems and potential. Vol. 4, Série Amazônia N.4. Belém, Brasil: IMAZOM. 42 pp. (in Portuguese).

Bins, L. S.; Erthal, G. J.; Fonseca, L. M. G. 1993. A method of unsupervised region classification. Simpósio Brasileiro de Computação Gráfica e Processamento de Imagens, 6 de outubro, Recife. (in Portuguese).

Bispo, P.d.C.; Valeriano, M.d.M.; Kuplich, T.M. 2009. Relation of local geomorphometric variables with the vegetation of the Madeira-Purus interfluve (AM/RO). Acta Amazonica, 39 (1):8190. (in Portuguese).

Bunker, S.G. 1982. Credit programs and non-intentional disintegration of extractive export economies in the Middle Amazon (PA). Pesq. Plan. Econ., 12 (1):231-60. (in Portuguese).

Câmara, G.; Souza, R.C.M.; Freitas, U.M.; Garrido, J. 1996. SPRING: Integrating remote sensing and GIS by object-oriented data modelling. Computers \& Graphics, 20:395-403.

Câmara, G.; Valeriano, D.d.M.; Soares, J.V. 2006. Calculation method of annual deforestation rate in Amazon. São José dos Campos: INPE. (in Portuguese).

Congalton, R.G.; Green, K. 1999. Assessing the accuracy of remotely sensed data: principles and practices. New York: Lewis Publishers. 137 pp.

Costa, M.P.F.; Telmer, K.H.; Novo, E.M.L.M. 2007. Spectral light attenuation in Amazonian Waters: land change use implications. I Simpósio da Rede GEOMA, 2007, Petrópolis, Brasil. (in Portuguese).

Denevan, W.M. 1996. A bluff model of riverine settlement in prehistoric Amazonia. Annals of the Association of American Geographers 86:654-81.

DNPM. 1976. Radambrasil Project: Geology, Geomorphology, Pedology, Vegetation and Land Use Potential. Folha SA. 21 Santarém, Vol. 10, (Levantamentos de Recursos Naturais) Rio de Janeiro: DNPM. 519 pp. (in Portuguese).

Hess, L.L.; Melack, J.M.; Novo, E.M.L.M.; Barbosa, C.C.; Gastil, M. 2003. Dual-season mapping of wetland inundation and vegetation. Remote Sensing of Environment, 87:404-28.

IBGE, Instituto Brasileiro de Geografia e Estatística. 2004. Vegetation Map of Brazil. Ministério do Planejamento, Orçamento e Gestão. Diretoria de Geociências. (in Portuguese).

Mather, P.M. 2005. Computer processing of remotely-sensed images. Chichester, England: John Wiley \& Sons.

McGrath, D.G.; Almeida, O.T.; Merry, F.D. 2006. The Influence of Community Management Agreements on Household Economic Strategies: Cattle Grazing and Fishing Agreements on the Lower Amazon Floodplain. XI Biennial Global Conference of The International Association for the Study of Common Property (IASCP), 19 - 23 junho de 2006, Bali, Indonesia. 
Melack, J.M.; Hess, L.L.; Gastil, M.; Forsberf, B.R.; Hamilton, S.K.; Lima, I.B.T.; Novo, E.M.L.M. 2004. Regionalization of methane emissions in the Amazon basin with microwave remote sensing. Global Change Biology, 10:530-44.

Novo, E.M.L.M.; Affonso, A.G.; Melack, J.M. 2007. Multisensor approaches to assess the relationship between wetland deforestation and Amazon floodplain lake eutrophication. XIII Simpósio Brasileiro de Sensoriamento Remoto, 2007, Florianópolis, Brasil.

Roosevelt, A.C. 2000. The Lower Amazon: a dynamic human habitat. In Imperfect Balance: Landscape Transformations in the Pre-Columbian Americas, editado por D. L. Lentz. New York.

Sheikh, P.A.; Merry, F.D.; McGrath, D.G. 2006. Water buffalo and cattle ranching in the Lower Amazon Basin: Comparisons and conflicts. Agricultural Systems, 87:313-30.

Shimabukuro, Y.E.; Novo, E.M.L.M.; Leal, A.K.M. 1998. LandsatTM digital mosaic of Solimóes-Amazonas River floodplain (Brazil). São José dos Campos: INPE. (in Portuguese).

Shimabukuro, Y.E.; Smith, J.A. 1991. The least-squares mixing models to generate fraction images derived from remote sensing multispectral data. IEEE Transactions on Geosciences \& Remote Sensing 29 (1):16 - 20.

Smith, N.J.H. 1999. The Amazon River Forest: A Natural History of Plants, Animals, and People Oxford: Oxford Univ. Press.

Winklerprins, A.M.G.A. 2006. Jute cultivation in the lower Amazon, 1940-1990: an ethnographic account from Santarém, Pará, Brazil. Journal of Historical Geography, 32 (4):818-38.

Wittmann, F.; Junk, W.J.; Piedade, M.T.F. 2004. The várzea forests in Amazonia: flooding and the highly dynamic geomorphology interact with natural forest succession. Forest Ecology and Management, 196 (2-3):199-212.

Wittmann, F.; Schöngart, J.; Montero, J.C.; Motzer, T.; Junk, W.J.; Piedade, M.T.F.; Queiroz, H.L.; Worbes, M. 2006. Tree species composition and diversity gradients in white-water forests across the Amazon Basin. Journal of Biogeography, 33 (8):1334-47.

Recebido em 18/11/2009

Aceito em 25/03/2010 